\title{
Tolumonas auensis gen. nov., sp. nov., a Toluene-Producing Bacterium from Anoxic Sediments of a Freshwater Lake
}

\author{
C. FISCHER-ROMERO, ${ }^{1}$ B. J. TINDALL, ${ }^{2}$ AND F. JÜTTNER ${ }^{1 *}$ \\ Institut für Pflanzenbiologie, Limnologische Station, Universität Zürich, 8802 Kilchberg, Switzerland, ' and Deutsche \\ Sammlung von Mikroorganismen und Zellkulturen GmbH, 38124 Braunschweig, Germany ${ }^{2}$
}

\begin{abstract}
A new toluene-producing bacterium, strain $\mathrm{TA} 4^{\mathrm{T}}(\mathrm{T}=$ type strain), was isolated from anoxic sediments of a freshwater lake. The individual cells of this organism were nonmotile, gram-negative rods that were 0.9 to 1.2 by 2.5 to $3.2 \mu \mathrm{m}$. The optimum temperature and $\mathrm{pH}$ for growth were $22^{\circ} \mathrm{C}$ and $\mathrm{pH} 7.2$, respectively. The $\mathrm{G}+\mathrm{C}$ content of the DNA was $49 \mathrm{~mol} \%$. Toluene was produced from phenylalanine, phenylpyruvate, phenyllactate, and phenylacetate, and phenol was produced from tyrosine. Both the presence of a carbon source and the presence of a toluene precursor were essential for initiation of toluene production. Bacterial growth occurred under oxic and anoxic conditions. Acetate, ethanol, and formate were the major fermentation products of the bacterium when it was grown on glucose. The major lipoquinones were ubiquinone 8 and menaquinone 8 under both oxic and anoxic growth conditions. On the basis of the results of a $16 \mathrm{~S}$ ribosomal DNA sequence analysis, we concluded that this organism is a member of the $\gamma$ subclass of the Proteobacteria, and we suggest the name Tolumonas auensis for this species.
\end{abstract}

Anoxic waters are inhabited by a wide variety of bacteria, including sulfate reducers and methanogens, which have been studied extensively (21). The products of the sulfate reducers and methanogens, sulfide and methane, can be detected easily in water. Methane is produced almost exclusively by methanogens, and a major part of the sulfide found in anoxic lake water is the result of reduction of sulfate ions by sulfate reducers. However, in the anoxic parts of many freshwater lakes other compounds also accumulate, and the presence of these compounds cannot be explained by the activity of sulfate reducers and methanogens. One such compound is the aromatic hydrocarbon toluene, which has recently been detected at high concentrations ( $>3 \mu \mathrm{g} /$ liter) in anoxic hypolimnia of several small lakes (9). This compound accumulated during the course of the year in the hypolimnion of a eutrophic lake, and accumulation began as soon as stratification of the water occurred and anoxic conditions were established (11). The time course of toluene accumulation clearly points to microbial production of this compound, and this finding makes the rather popular use of toluene as a tracer of pollution questionable. The bacteria responsible for toluene production in lakes are not known yet. In a previous study, microbial production of toluene in artificial anoxic lake water inoculated with lake sediment was observed under laboratory conditions (10), but it was not clear which organisms were responsible for this production. Inhibitor experiments performed with 2-bromoethanesulfonate and molybdate revealed that the sulfate reducers and methanogens are not involved in production of toluene (unpublished data). In this paper we describe the isolation of a toluene-producing microorganism from anoxic lake sediments; this organism represents a new species of a new genus belonging to the $y$ subclass of the Proteobacteria.

\section{MATERIALS AND METHODS}

Media and cultivation conditions. The basal toluene production medium (TP medium) that was used for enrichment, isolation, and cultivation was a modified medium described by Eichler and Pfennig (3); however, the concentrations of

* Corresponding author. Mailing address: Institut für Pflanzenbiologie, Limnologische Station, Universität Zürich, Seestrasse 187, 8802 Kilchberg, Switzerland. sodium sulfide and glucose were reduced to $5 \mathrm{mmol} /$ liter and $1 \mathrm{~g} / \mathrm{liter}$, respectively, and $10 \mathrm{mg}$ of yeast extract per liter and $0.4 \mathrm{mmol}$ of phenylalanine per liter were added.

The following procedures were used to obtain anoxic growth conditions. TP medium was prepared in $2,365-\mathrm{ml} \mathrm{screw}$-cap bottles, and the $\mathrm{pH}$ was adjusted $\mathrm{to}$ 7.2. Before sodium sulfide was added, each solution was purged with argon for 10 min to remove oxygen. To obtain liquid cultures, the bottles were inoculated, and each bottle was sealed with a silicone rubber septum lined with Teflon-coated aluminum foil. These cultures were incubated at $22^{\circ} \mathrm{C}$ in the dark without shaking. For solid TP medium, double-strength TP medium was prepared, transferred to a closed cabinet (Anaerobic System 1029; Forma Scientific Inc., Marietta, Ohio), and mixed with $2 \%$ agar under a nitrogen atmosphere. For experiments performed under oxic conditions TP medium was prepared without sodium sulfide and protection from air in 300 -ml flasks.

Enrichment and isolation. Enrichment for toluene-producing organisms was carried out in anoxic TP medium prepared as described above. The medium was inoculated with $5 \mathrm{ml}$ of anoxic freshwater sediment per liter; this sediment was obtained from shallow eutrophic Lake Au (a separate part of Lake Zürich in Switzerland). When the toluene concentration in the bottles was equal to the concentration of the added phenylalanine, $5-\mathrm{ml}$ aliquots of the cultures were transferred to fresh TP medium. This procedure was repeated until the morphological features of the bacterial population became stable. Aliquots of the resulting liquid culture were used to isolate toluene-producing bacteria by the agar deep dilution method (18). The procedures were repeated until a pure tolueneproducing culture was obtained. The purity of the culture was determined microscopically and by plating it on solid TP medium.

Morphology. The shapes and sizes of living and stained cells were determined by light microscopy. The search for flagella was performed with a model $\mathrm{H} 7000$ transmission electron microscope (Hitachi) after preparations were stained with 0.5 to $2 \%$ phosphotungstic acid. The Gram reaction was determined by light microscopy after cells were treated by methods described in the Anaerobe laboratory manual (5).

Environmental effects. The effects of $\mathrm{pH}$ and temperature on growth were determined on TP medium. Medium $\mathrm{pH}$ values between 5.0 and 8.5 were obtained by adding $50 \mathrm{mmol}$ of MES [2-( $N$-morpholino)ethanesulfonic acid] per liter, $50 \mathrm{mmol}$ of TES $[N$-tris(hydroxymethyl)methyl-2-aminocthanesulfonic acid] per liter, or $50 \mathrm{mmol}$ of Tricine [ $N$-tris(hydroxymethyl)methylglycine] per liter, and the $\mathrm{pH}$ was adjusted by using $\mathrm{NaOH}$. To determine the optimum temperature, cultures were incubated between 5 and $45^{\circ} \mathrm{C}$. The temperature and $\mathrm{pH}$ experiments were performed in triplicate.

The ability to grow in the presence of $\mathrm{O}_{2}$ was determined by cultivating the organisms on AC medium (catalog no. B 316; Difco) and TP medium. Catalase activity was detected by the presence of $\mathrm{O}_{2}$ bubbles after I drop of $5 \% \mathrm{H}_{2} \mathrm{O}_{2}$ was mixed with cells on a microscope slide. Cytochrome oxidase activity was detected with test strips (Bactident oxidase strips; Merck, Darmstadt, Germany).

Determination of toluene and phenylacetate concentrations. To determine the concentrations of toluene in the culture media, we used the method described by Jüttner $(8)$. The medium $(0.1$ to $75 \mathrm{ml})$ was supplemented with perdeuterotoluene $(1 \mu \mathrm{l}$ of perdeuterotoluene-ethanol $[1: 1,000, \mathrm{vol} / \mathrm{vol}])$ as an internal standard and stripped for $30 \mathrm{~min}$ in a closed-loop stripping apparatus. The toluene was adsorbed on a cartridge filled with $150 \mathrm{~g}$ of Tenax TA and was transferred by thermodesorption into a gas chromatograph-mass spectrometer. The toluene 
was separated by gas-liquid chromatography on a type DB 1301 fused-silica capillary column ( $30 \mathrm{~m}$ by $0.32 \mathrm{~mm}$; J \& W Scientific) and was detected by single-ion monitoring $(\mathrm{m} / \mathrm{z} 91$ and $\mathrm{m} / \mathrm{z} 98)$ with a Hewlett-Packard model $5970 \mathrm{~A}$ mass spectrometer.

Phenylacetate was esterified with $20 \%$ (wt/vol) $\mathrm{BF}_{3}-$ methanol. The methyl ester obtained was extracted with tert-butylmethyl ether and analyzed by gas chromatography-mass spectrometry.

Growth on tyrosine. The ability of the bacterium to utilize tyrosine in place of phenylalanine was determined in anoxic TP medium supplemented with 0.4 mimol of tyrosine per liter. The products formed were extracted by stripping under salting-out conditions $(20 \%$ [wt/ $/ \mathrm{vol}] \mathrm{NaCl})$, separated, and analyzed by gas chromatography-mass spectrometry as described above for toluene.

Substrate utilization and fermentation products. Utilization of substrates was determined in anoxic TP medium in which glucose was replaced by different carbon sources that were added at concentrations of $30 \mathrm{mmol}$ of $\mathrm{C}$ per liter. The optical density, pH, and amount of toluene produced were determined for each of these cultures. The assays were performed in triplicate. The ability to use 95 different organic compounds in the presence of air was determined with GN MicroPlate test panels (Biolog, Inc., Hayward, Calif.) as recommended by the supplier.

The compositions of the fermentation products (volatile acids, alcohols, and nonvolatile acids) were determined in TP medium and peptone-yeast extractglucose broth. These analyses were performed as described by Levett (12) by using gas chromatography, an FFAP fused-silica capillary column ( $30 \mathrm{~m}$ by 0.32 $\mathrm{mm}$; film thickness, $0.25 \mu \mathrm{m}$; J \& W Scientific), and a flame ionization detector. Formate concentrations were determined by gas chromatography-mass spectrometry.

Biochemical tests. Gelatin hydrolysis, urease activity, indole production, and $\mathrm{H}_{2} \mathrm{~S}$ formation tests were performed by using the API $20 \mathrm{E}$ test system (bioMérieux, La Balme les Grottes, France) as recommended by the supplier. Lipase activity and lecithinase activity tests were performed as described by Süssmuth et al. (15).

Respiratory lipoquinones and polar lipids. Respiratory lipoquinones and polar lipids were extracted from $100 \mathrm{mg}$ of freeze-dried material by using the two-stage method described by Tindall $(16,17)$. Briefly, cell material was stirred in hexane-methanol $(1: 2 ; \mathrm{vol} / \mathrm{vol})$ and placed on ice, and the respiratory lipoquinones were recovered in the hexane layer by adding 1 volume of cold hexane. The hexane phase was removed, and the respiratory lipoquinones were extracted a second time from the methanol phase by adding 2 volumes of hexane and 2 volumes of $0.3 \%$ aqueous $\mathrm{NaCl}$. The hexane phases were pooled and used for the lipoquinone analysis. Polar lipids were extracted by adjusting the methanol- $0.3 \%$ aqueous $\mathrm{NaCl}$ phase until the ratio of chloroform to methanol to $0.3 \%$ aqueous $\mathrm{NaCl}$ was 1:2:0.8 ( $\mathrm{vol} / \mathrm{vol} / \mathrm{vol})$. The extraction solvent was stirred, and the cell debris was removed by centrifugation. Polar lipids were recovered in the chloroform phase by adjusting the ratio of chloroform to methanol to $0.3 \%$ aqueous $\mathrm{NaCl}$ to $1: 1: 0.9(\mathrm{vol} / \mathrm{vol} / \mathrm{vol})$

The respiratory lipoquinones were separated into different classes (menaquinones and ubiquinones) by thin-layer chromatography on silica gel (catalog no. 805023; Macherey-Nagel) plates by using hexane-tert-butylmethyl ether as the solvent. The UV-absorbing bands corresponding to menaquinones and ubiquinones were removed from the plates and were analyzed by high-performance liquid chromatography (HPLC). The HPLC analysis was performed with a model LDC analytical HPLC (Thermoseparations) equipped with a reversedphase column ( $\mathrm{RP}_{18} ; 2$ by $125 \mathrm{~mm}$; particle size, $3 \mu \mathrm{m}$; Macherey-Nagel); meth anol was used as the eluant, and respiratory lipoquinones were detected at 269 $\mathrm{nm}$.

Polar lipids were separated by two-dimensional silica gel thin-layer chromatography (catalog no. 818135; Macherey-Nagel); the plates were developed with chloroform-methanol-water $(65: 25: 4, \mathrm{vol} / \mathrm{vol} / \mathrm{vol})$ in the first direction and with chloroform-methanol-acetic acid-water $(80: 12: 15: 4 \mathrm{vol} / \mathrm{vol} / \mathrm{vol} / \mathrm{vol})$ in the second direction. The total-lipid material and specific functional groups were detected by using the following spray reagents: dodecamolybdophosphoric acid (tota lipids), Zinzadze reagent (phosphate), ninhydrin (free amino groups), periodateSchiff reagent ( $\alpha$-glycols), Dragendorff reagent (quaternary nitrogen), and anisaldehyde-sulfuric acid (glycolipids)

Fatty acid profile. Fatty acids were analyzed as their methyl ester derivatives, which were prepared from $20 \mathrm{mg}$ of dry cell material. The methods used allowed for selective hydrolysis of ester- and amide-linked fatty acids (17a). Fatty acid methyl esters were analyzed by gas chromatography by using a nonpolar capillary column $(0.2 \mathrm{~mm}$ by $25 \mathrm{~m})$ and a flame ionization detector. The following conditions were used: injection port and detector temperature, $300^{\circ} \mathrm{C}$; inlet pressure, $60 \mathrm{kPa}$; split ratio, 50:1; injection volume, $1 \mu \mathrm{l}$; and a temperature program in which the temperature increased from 130 to $310^{\circ} \mathrm{C}$ at a rate of $4^{\circ} \mathrm{C} / \mathrm{min}$.

DNA base composition. To determine the DNA base composition, cells were disrupted by treatment with a French press and the DNA was purified on hydroxyapatite by the procedure described by Cashion et al. (1). The DNA obtained was treated with P1 nuclease and alkaline phosphatase, and the resulting deoxyribonucleotides were analyzed by HPLC. The G+C content was cal culated by the method described by Mesbah et al. (13)

Phylogenetic analysis. A phylogenetic analysis in which 16 S ribosomal DNA (rDNA) sequences were used was performed by A. Rainey (Deutsche Sammlung von Mikroorganismen und Zellkulturen, Braunschweig, Germany). Genomic

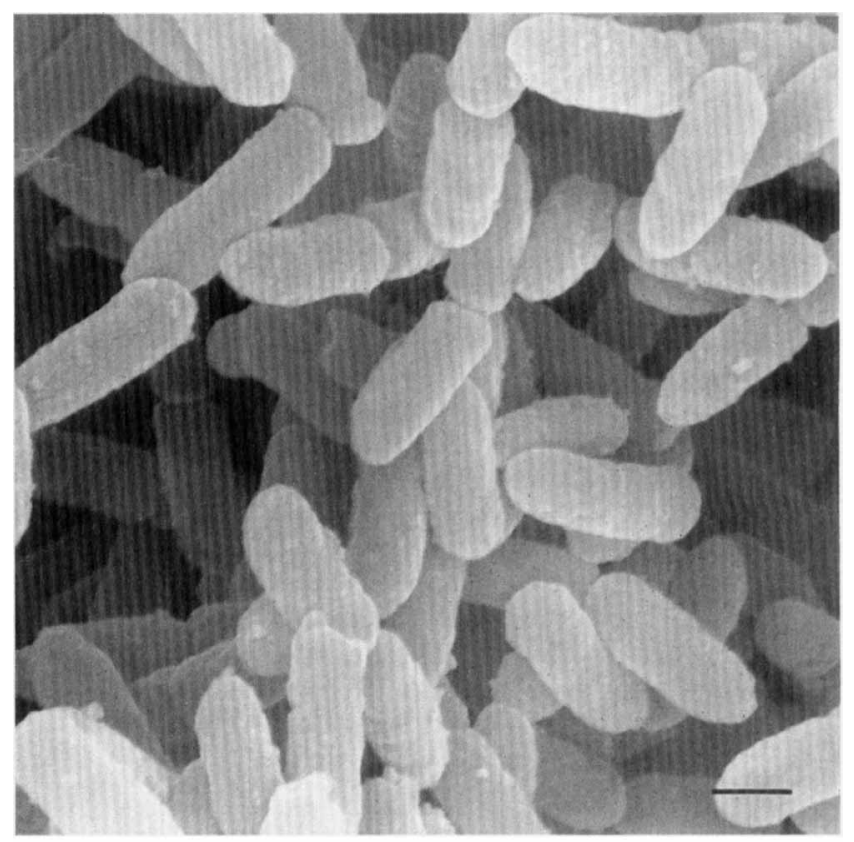

FIG. 1. Scanning electron micrograph of strain TA $4^{\mathrm{T}}$. Bar $=1 \mu \mathrm{m}$.

DNA was extracted, PCR-mediated amplification of the 16S rDNA was performed, and PCR products were purified as described by De Soete (2) and Jukes and Cantor (7). The sequences of purified PCR products were determined by using a Taq DyeDeoxy terminator cycle sequencing kit (Applied Biosystems, Weiterstadt, Germany) as recommended by the manufacturer. Sequence reaction mixtures were separated by electrophoresis by using an Applied Biosystems model 373A DNA sequencer. The $16 \mathrm{~S}$ rDNA sequence which was determined manually aligned with representative rDNA sequences of members of the gamma subclass of the Proteobacteria.

Pairwise evolutionary distances were computed by using the correction of Jukes and Cantor (7). The least-squares distance method of De Soete (2) was used to construct a phylogenetic dendrogram from the distance matrix data.

Nucleotide sequence accession number. The nucleotide sequence which we determined has been deposited in the EMBL database under accession number X92889.

\section{RESULTS}

Enrichment and isolation. Using the enrichment and isolation techniques described above, we obtained five bacterial strains (strains TA 1, TA 2 , TA 3 , TA $44^{\mathrm{T}}[\mathrm{T}=$ type strain], and TA 5) that differed in colony morphology from anoxic freshwater sediments. However, when these organisms were transferred into liquid medium and tested for toluene production, only strain TA $4^{\mathrm{T}}$ was capable of both growth and toluene production. This strain was used for all further experiments.

Morphology. The individual cells of strain TA $4^{\mathrm{T}}$ were nonmotile rods that were 2.5 to $3.2 \mu \mathrm{m}$ long and 0.9 to $1.2 \mu \mathrm{m}$ wide (Fig. 1). They occurred singly and in pairs. The colonies observed on agar plates and agar deeps were 0.3 to $0.5 \mathrm{~mm}$ in diameter, lens shaped, and white. The organism was gram negative, but in the early growth stage the outer parts of the cells were not decolorized.

Toluene formation and substrate utilization. Strain TA $4^{\mathrm{T}}$ was able to transform phenylalanine, phenyllactate, phenylpyruvate, and phenylacetate into toluene (Fig. 2) and tyrosine into phenol. Production of toluene occurred only when one of these precursors and one of the carbon sources described below were present. Strain TA $4^{\mathrm{T}}$ grew anaerobically on all of the sugars tested except cellulose, fucose, lactose, and xylose (Table 1). Of the polyalcohols tested, only mannitol and sorbitol supported growth. No growth was observed on thy- 


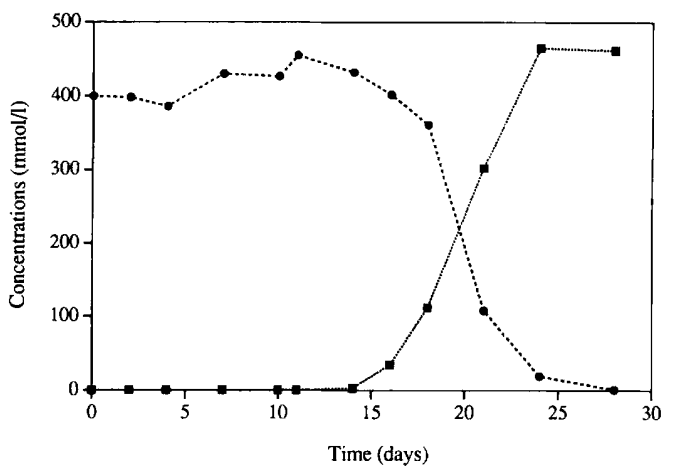

FIG. 2. Toluene ( $\mathbf{\square}$ ) and phenylacetic acid ( $)$ concentrations during anaerobic growth of strain TA $4^{\mathrm{T}}$ in TP medium containing phenylacetic acid as a toluene precursor.

mine, organic acids, and inorganic compounds. The major fermentation products of glucose in peptone-yeast extract-glucose cultures were ethanol, acetate, and formate.

In the presence of air, strain $\mathrm{TA} 4^{\mathrm{T}}$ catabolized the following organic substrates when analyzed with the 24-h MicroPlate test: Tween 40 , Tween 80 , L-arabinose, D-fructose, D-galactose, D-glucose, methylpyruvate, monomethylsuccinate, acetic acid, cis-aconitic acid, D-galacturonic acid, D-gluconic acid, D-glucuronic acid, $\beta$-hydroxybutyric acid, $\alpha$-ketoglutaric acid, DL-lactic acid, malonic acid, quinic acid, sebacic acid, succinic acid, glucuronamide, L-alanine, L-asparagine, L-aspartic acid, L-glutamic acid, L-histidine, L-threonine, urocanic acid, and inosine. The following organic substrates were not catabolized under oxic conditions in the 24-h MicroPlate test: $\alpha$-cyclodextrin, dextrin, glycogen, $N$-acetyl-D-galactosamine, $N$-acetyl-D-glucosamine, adonitol, D-arabitol, cellobiose, i-erythritol, L-fucose, gentiobiose, $m$-inositol, $D$-lactose, lactulose, maltose, D-mannitol, D-mannose, D-melibiose, $\beta$-methyl-D-glucoside, D-psicose, D-raffinose, L-rhamnose, D-sorbitol, sucrose, D-trehalose, turanose, xylitol, citric acid, formic acid, D-galactonic acid lactone, D-glucosaminic acid, $\alpha$-hydroxybutyric acid, $\gamma$-hydroxybutyric acid, $p$-hydroxyphenylacetic acid, itaconic acid, $\alpha$-ketobutyric acid, $\alpha$-ketovaleric acid, propionic acid, D-saccharic acid, bromosuccinic acid, succinamic acid, alaninamide, D-alanine, Lalanyl-glycine, glycyl-L-aspartic acid, glycyl-L-glutamic acid, hydroxy-L-proline, L-leucine, L-ornithine, L-phenylalanine, Lproline, L-pyroglutamic acid, D-serine, L-serine, DL-carnitine, $\gamma$-aminobutyric acid, uridine, thymidine, phenylethylamine, putrescine, 2-aminoethanol, 2,3-butanediol, glycerol, DL- $\alpha$ glycerophosphate, glucose 1-phosphate, and glucose 6-phosphate.

Effects of $\mathbf{p H}$, temperature, and $\mathbf{O}_{2}$. Cell growth occurred at $\mathrm{pH} 6.0$ to 7.5 ; no growth occurred at $\mathrm{pH} 5.5$ and 8.0. The organism grew at temperatures between 12 and $25^{\circ} \mathrm{C}$, and the optimum temperature was $22^{\circ} \mathrm{C}$. Very little growth occurred at $30^{\circ} \mathrm{C}$. Since toluene production ceased after 1 month of incubation, this period of time was used for the growth experiments. The effects of temperature and $\mathrm{pH}$ on the specific rate of toluene production are shown in Fig. 3. Two or three independent experiments were performed for each set of conditions.

Strain TA $4^{\mathrm{T}}$ grew in the presence of $\mathrm{O}_{2}$. Catalase and oxidase were not produced in anaerobic cultures; aerobic cultures were catalase positive but oxidase negative. Toluene production was also observed in aerobic cultures.

Biochemical tests. The short-time tests were negative for the enzymes lipase, lecithinase, urease and exoprotease (gelatin
TABLE 1. Effects of different carbon sources on the growth and toluene production of strain TA $4^{\mathrm{T}}$ after 17 days of incubation in anaerobic TP medium

\begin{tabular}{|c|c|c|}
\hline Carbon source & Growth & Toluene production ${ }^{a}$ \\
\hline D-Arabinose & + & 20 \\
\hline D-Cellobiose & + & 22 \\
\hline Cellulose & - & 0 \\
\hline D-Fructose & + & 28 \\
\hline L-Fucose & - & 0 \\
\hline D-Glucose & + & 27 \\
\hline Glycogen & + & 50 \\
\hline Inulin & + & $<1$ \\
\hline D-Lactose & - & 0 \\
\hline Maltose & + & 25 \\
\hline D-Mannose & + & 49 \\
\hline D-Melezitose & + & $\mathrm{ND}^{b}$ \\
\hline Melibiose & + & ND \\
\hline D-Raffinose & + & ND \\
\hline L-Rhamnose & + & ND \\
\hline D-Ribose & + & $<1$ \\
\hline Salicin & + & ND \\
\hline Sucrose & + & 20 \\
\hline D-Trehalose & + & ND \\
\hline D-Xylose & - & 0 \\
\hline Adonitol & - & 0 \\
\hline Dulcitol & - & 0 \\
\hline Glycerol & - & 0 \\
\hline Inositol & - & 0 \\
\hline D-Mannitol & + & 17 \\
\hline Methanol & - & 0 \\
\hline D-Sorbitol & + & 15 \\
\hline Thymine & - & 0 \\
\hline Acetate & - & 0 \\
\hline Formate & - & 0 \\
\hline Fumarate & - & 0 \\
\hline L-Lactate & - & 0 \\
\hline L-Malate & - & 0 \\
\hline Propionate & - & 0 \\
\hline Pyruvate & - & 0 \\
\hline $\mathrm{HCO}_{3}^{-}$ & - & 0 \\
\hline $\mathrm{HCO}_{3}^{-}+\mathrm{H}_{2}$ & - & 0 \\
\hline None & - & 0 \\
\hline
\end{tabular}

${ }^{a}$ Toluene production is expressed in moles percent of the phenylacetate added.

${ }^{b} \mathrm{ND}$, not determined.

hydrolysis). There was no indication that strain TA $4^{\mathrm{T}}$ formed indole and $\mathrm{H}_{2} \mathrm{~S}$.

Respiratory lipoquinone and polar lipids. An examination of the respiratory lipoquinone composition of strain TA $4^{\mathrm{T}}$ showed that both ubiquinones and menaquinones were present whether the organism was cultivated under oxic or anoxic conditions. The major ubiquinone was ubiquinone $8(\mathrm{Q}-8)$ and the major menaquinone was menaquinone 8 (MK-8) under oxic and anoxic conditions. However, under oxic conditions a second menaquinone appeared; this menaquinone could not be identified unambiguously, but it had a chain length similar to the chain length of a methylated menaquinone. The polar lipid pattern showed that phosphatidylglycerol and phosphatidylethanolamine were the major phospholipids present.

Fatty acid profile. The fatty acid compositions under oxic and anoxic conditions were similar; the major fatty acids were $12: 0,14: 0,16: 0,16: 1 \omega 7 \mathrm{cis}, 18: 0$, and $18: 1 \omega 7 \mathrm{cis}$, as well as the 

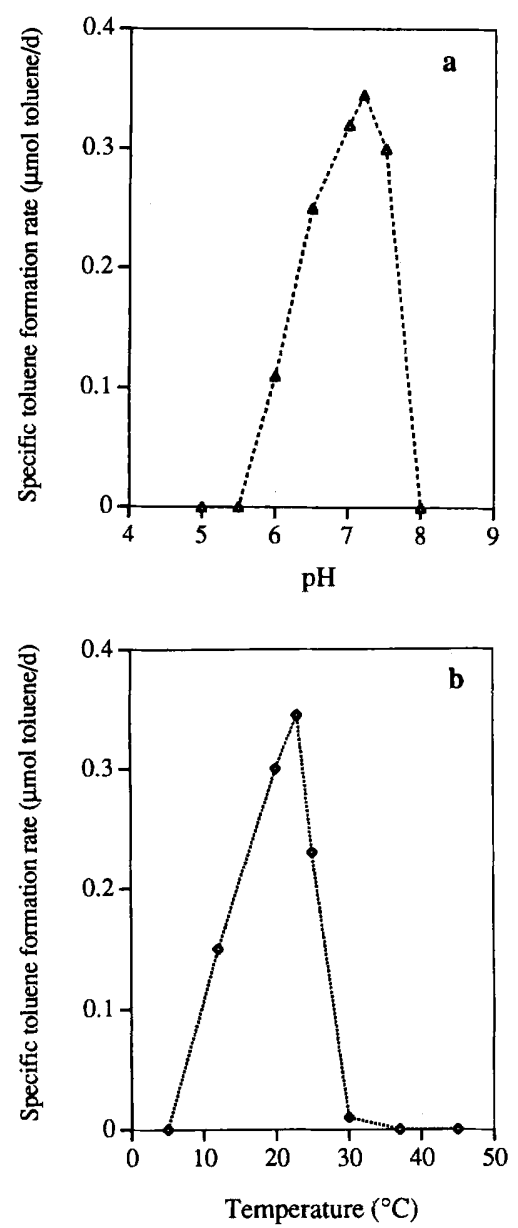

FIG. 3. Effects of $\mathrm{pH}(\mathrm{a})$ and temperature (b) on specific rates of toluene formation in strain TA 4 T.

hydroxylated fatty acid 3-OH 14:0. Using cleavage conditions selective for ester- and amide-bound fatty acids, we found that one-half of the 3-OH 14:0 fatty acid was amide bound and the rest of this acid and the other fatty acids were ester linked.

Phylogenetic analysis and $\mathbf{G}+\mathbf{C}$ content. A matrix of sequence similarity values for strain TA $4^{\mathrm{T}}$ and selected reference organisms belonging to the $\gamma$ subclass of the Proteobacteria is shown in Table 2, and the corresponding phylogenetic tree is shown in Fig. 4. The $\mathrm{G}+\mathrm{C}$ content of the DNA of strain TA $4^{\mathrm{T}}$ was 49 mol\%.

\section{DISCUSSION}

The biochemical and physiological characteristics of strain TA $4^{\mathrm{T}}$, a gram-negative rod-shaped bacterium, placed it in the group of facultatively anaerobic microorganisms in group 5 in Bergey's Manual of Determinative Bacteriology, 9th ed. (6). This group of microorganisms has been shown to represent a distinct lineage within the $\gamma$ subclass of the Proteobacteria, as determined by $16 \mathrm{~S}$ rDNA sequencing, and the inclusion of strain TA $4^{\mathrm{T}}$ in this group was confirmed by the $16 \mathrm{~S}$ rDNA sequencing results. However, there are also characteristics which allow strain TA $4^{\mathrm{T}}$ to be separated from the genera of this group.

The $G+C$ content of the DNA of strain TA $4^{\mathrm{T}}$ was $49 \mathrm{~mol} \%$. This value is within the range of values obtained for the fol- lowing phylogenetically related genera (6): Escherichia (G+C content, 48 to $52 \mathrm{~mol} \%$ ), Citrobacter (50 to $52 \mathrm{~mol} \%$ ), Hafnia (48 to 49 mol\%), Plesiomonas (51 mol\%), Serratia (52 to 60 mol\%), and Vibrio (38 to $51 \mathrm{~mol} \%$ ). However, it differs from the values obtained for members of the most closely related genus, the genus Aeromonas (57 to $63 \mathrm{~mol} \%$ ). Inclusion of strain TA $4^{\mathrm{T}}$ in one of the genera mentioned above is not possible because other characteristics supporting such a relationship are missing. For example, Citrobacter, Vibrio, and Plesiomonas strains are motile, the optimum temperature for Escherichia strains is $37^{\circ} \mathrm{C}$, and Hafnia and Serratia strains are able to utilize different carbon sources (glycerol and fucose, respectively). Strain TA $4^{\mathrm{T}}$ was catalase positive and oxidase negative. These characteristics are consistent with membership in the Enterobacteriaceae but distinguish strain TA $4^{\mathrm{T}}$ from the genera Aeromonas and Vibrio (6).

The polar lipid pattern revealed that phosphatidylglycerol and phosphatidylethanolamine were the major phospholipids present, as has been reported for many members of the $\beta$ and $\gamma$ subclasses of the Proteobacteria. However, a number of additional polar lipids are also produced by strain TA $4^{\mathrm{T}}$, and it is these lipids that may allow differentiation of groups of organisms that exhibit the highest levels of $16 \mathrm{~S}$ rDNA similarity to strain TA $4^{\mathrm{T}}$. Unfortunately, such detailed data for the other organisms are lacking.

Lipoquinone analysis does not generally have a high resolving power and often allows allocation of a strain only to a higher taxonomic unit. The presence of both Q-8 and MK-8 in strain TA $4^{\mathrm{T}}$ clearly indicates that this strain should be placed in the $\gamma$ subclass of the Proteobacteria on the basis of our knowledge about lipoquinone compositions. Within this group there are a number of groups of organisms which produce both menaquinones and ubiquinones. Although the lipoquinone data exclude strain TA $4^{\mathrm{T}}$ from most of the genera mentioned above and suggest that it could be included in certain groups belonging to the genus Vibrio, this conclusion is not supported by other data that indicate the possibly novel taxonomic status of the strain.

Many members of the Pasteurella-Haemophilus group, the Enterobacteriaceae, and the Aeromonas species tested produce Q-8, MK-8, and demethylated MK-8 (DMK-8). In contrast, some Vibrio species produce Q-8 and MK-8 or just Q-8. Strain TA $4^{\mathrm{T}}$ produced Q-8 and MK-8 but not DMK- 8 , although it produced another menaquinone that had an elution time longer than that of DMK-8.

The fatty acid pattern analysis revealed many features which support inclusion of strain TA $4^{\mathrm{T}}$ in the group of organisms defined by the $16 \mathrm{~S}$ rDNA analysis. However, whether this strain should be included in the genus Aeromonas should be considered carefully. Members of the genus Aeromonas are characterized by the presence of several hydroxy fatty acids, including 3-OH iso-15:0 and (in all probability) 3-OH 14:0, and produce a range of saturated and unsaturated straight chain fatty acids, as well as lower levels of branched-chain fatty acids. On the basis of this characteristic alone, strain TA $4^{\mathrm{T}}$ should be excluded from the genus Aeromonas. Although the fatty acid 3-OH 14:0 appears to occur in many of the strains that exhibit levels of $16 \mathrm{~S}$ rDNA similarity with strain TA $4^{\mathrm{T}}$ of more than $88 \%$, this compound is often accompanied by additional hydroxylated fatty acids. The fatty acid patterns may also include branched-chain fatty acids that do not occur in strain TA $4^{\mathrm{T}}$. Only about $50 \%$ of 3-OH 14:0 fatty acid was amide bound; the remainder was ester linked. This is a characteristic that is typical of certain members of the family Enterobacteriaceae, in which one-half of the lipopolysaccharide-linked 3-OH 14:0 
TABLE 2. 16S rDNA similarity values for strain TA $4^{\mathrm{T}}$ and related taxa

\begin{tabular}{|c|c|c|c|c|c|c|c|c|c|c|c|c|c|c|c|}
\hline \multirow[b]{2}{*}{ Organism } & \multicolumn{15}{|c|}{$\% 16 \mathrm{~S}$ rDNA similarity } \\
\hline & 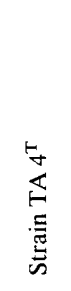 & 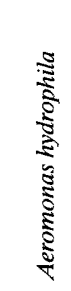 & 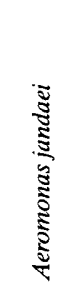 & 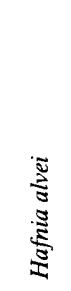 & 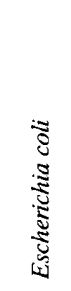 & 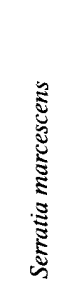 & 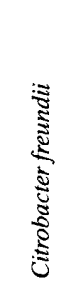 & 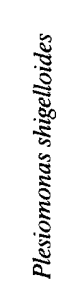 & 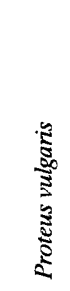 & 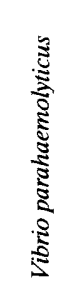 & 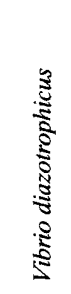 & 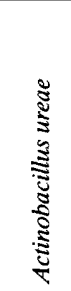 & 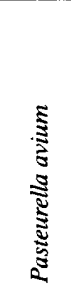 & 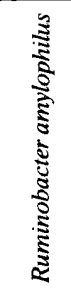 & 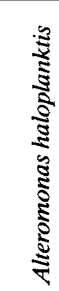 \\
\hline Aeromonas hydrophila & 91.0 & & & & & & & & & & & & & & \\
\hline Aeromonas jandaei & 90.6 & 98.3 & & & & & & & & & & & & & \\
\hline Hafnia alvei & 90.0 & 89.8 & 90.2 & & & & & & & & & & & & \\
\hline Escherichia coli & 89.9 & 89.9 & 90.4 & 94.8 & & & & & & & & & & & \\
\hline Serratia marcescens & 89.7 & 89.7 & 89.8 & 96.5 & 96.4 & & & & & & & & & & \\
\hline Citrobacter freundii & 89.7 & 89.4 & 90.0 & 96.2 & 97.4 & 97.3 & & & & & & & & & \\
\hline Plesiomonas shigelloides & 89.7 & 90.6 & 91.7 & 94.7 & 93.8 & 94.8 & 94.1 & & & & & & & & \\
\hline Proteus vulgaris & 89.1 & 88.9 & 89.7 & 95.0 & 93.4 & 94.3 & 93.4 & 93.1 & & & & & & & \\
\hline Vibrio parahaemolyticus & 87.9 & 88.7 & 88.4 & 90.2 & 90.1 & 90.5 & 90.5 & 91.0 & 89.4 & & & & & & \\
\hline Vibrio diazotrophicus & 86.8 & 88.5 & 89.1 & 90.3 & 90.5 & 90.7 & 91.0 & 91.0 & 89.2 & 95.3 & & & & & \\
\hline Actinobacillus ureae & 86.0 & 86.4 & 87.1 & 88.2 & 88.5 & 88.0 & 87.8 & 88.6 & 87.9 & 85.3 & 85.6 & & & & \\
\hline Pasteurella avium & 86.0 & 86.2 & 86.3 & 87.3 & 87.2 & 87.0 & 87.1 & 87.4 & 88.0 & 86.2 & 85.9 & 93.0 & & & \\
\hline Ruminobacter amylophilus & 88.2 & 87.5 & 87.7 & 86.4 & 86.9 & 86.7 & 86.5 & 86.6 & 86.2 & 85.3 & 84.8 & 85.8 & 85.4 & & \\
\hline Alteromonas haloplanktis & 86.1 & 88.2 & 88.0 & 88.0 & 87.9 & 88.0 & 88.2 & 89.1 & 86.5 & 89.1 & 88.6 & 84.9 & 85.5 & 85.7 & \\
\hline Legionella pneumophila & 83.6 & 84.4 & 84.9 & 84.8 & 84.1 & 84.4 & 84.2 & 85.3 & 84.2 & 85.8 & 85.2 & 84.1 & 83.2 & 84.1 & 85.8 \\
\hline
\end{tabular}

fatty acid is amide linked and the remainder is ester linked (19).

One significant characteristic of strain TA $4^{\mathrm{T}}$ was the ability to transform phenylalanine and other phenyl precursors into toluene. A few bacteria that are able to transform amino acids into aromatic hydrocarbons have been described. "Clostridium foetidum" transforms phenylalanine in a Stickland reaction with methionine into toluene (14). Lactobacillus sp. (20) and Clostridium sp. (4) strains liberate $p$-cresol and phenol from tyrosine. All of these organisms differ from strain TA $4^{\mathrm{T}}$ in their cytophysiological characteristics and in the biochemistry of toluene production.

On the basis of the data described above, we concluded that strain TA $4^{\mathrm{T}}$ is a member of a new species of a new genus belonging to the $\gamma$ subclass of the Proteobacteria. We propose the name Tolumonas auensis gen. nov., sp. nov. for this bacterium.

Description of Tolumonas gen. nov. Tolumonas (To.lu.mo'nas. L. n. toluolum, toluene; L. n. monas, unit; M.L. fem. n. Tolumonas, toluene-producing unit). Cells are nonmotile, gram-negative rods ( 2.5 to 3.2 by 0.9 to $1.2 \mu \mathrm{m}$ ) and occur singly and in pairs. Growth occurs under oxic and anoxic conditions. Anaerobic cultures are catalase and oxidase negative; aerobic cultures are catalase positive and oxidase negative. Toluene is produced from phenylalanine, phenylacetate, phenyllactate, and phenylpyruvate only in the presence of a carbon source. The major fermentation products in peptone-yeast extract-glucose cultures are ethanol, acetic acid, and formic acid. Phenol is produced when phenylalanine is replaced by tyrosine. The optimal conditions for growth are $22^{\circ} \mathrm{C}$ and $\mathrm{pH} 7.2$. Indole and $\mathrm{H}_{2} \mathrm{~S}$ are not formed. According to the results of a sequence analysis of its 16S rDNA, this genus belongs to the $\gamma$ subclass of the Proteobacteria.

The type species is Tolumonas auensis.

Description of Tolumonas auensis sp. nov. Tolumonas auensis (au.en'sis. M.L. gen. n. auensis of Lake Au, the first source of this organism). In addition to the characteristics of the genus, the species has the characteristics described below.
Under anoxic conditions D-arabinose, D-cellobiose, $D$-fructose, D-glucose, glycogen, inulin, maltose, D-mannose, D-melezitose, melibiose, D-raffinose, L-rhamnose, D-ribose, salicin, sucrose, D-trehalose, D-mannitol, and D-sorbitol are used as carbon sources. In the presence of air the following organic compounds are catabolized: Tween 40, Tween 80 , L-arabinose, D-fructose, D-galactose, D-glucose, methyl pyruvate, monomethylsuccinate, acetic acid, cis-aconitic acid, D-galacturonic acid, D-gluconic acid, D-glucuronic acid, $\beta$-hydroxybutyric acid,

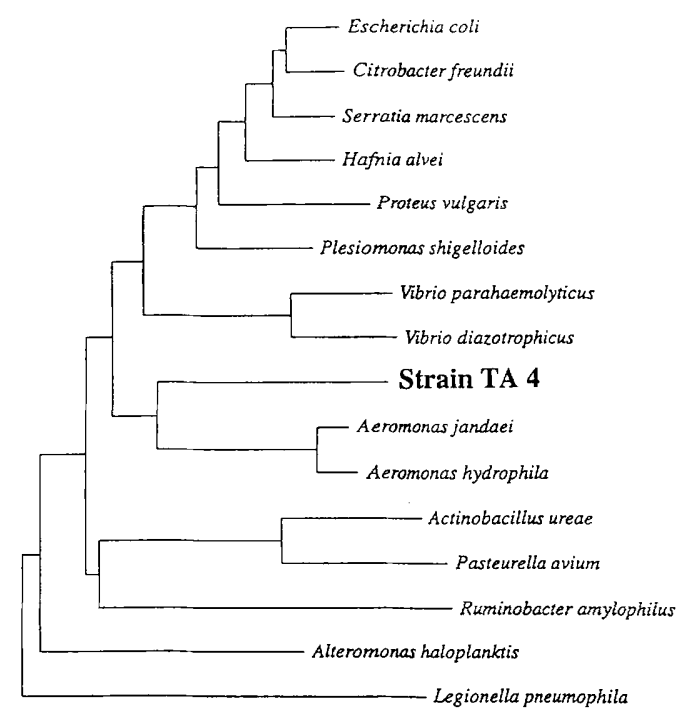

0.05

FIG. 4. Phylogenetic dendrogram showing the position of strain $\mathrm{TA} 4^{\mathrm{T}}$ within the radiation of representatives of the $\gamma$ subclass of the Proteobacteria. Scale bar $=5$ inferred nucleotide substitutions per 100 nucleotides. 
$\alpha$-ketoglutaric acid, DL-lactic acid, malonic acid, quinic acid, sebacic acid, succinic acid, glucuronamide, L-alanine, L-asparagine, L-aspartic acid, L-glutamic acid, L-histidine, L-threonine, urocanic acid, and inosine. The major lipoquinones are Q-8 and MK-8 under both oxic and anoxic growth conditions. The

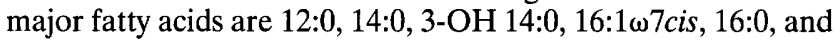
$18: 1 \omega 7$ cis. The $\mathrm{G}+\mathrm{C}$ content of the DNA is $49 \mathrm{~mol} \%$. The source of this organism was the anoxic sediment of a freshwater lake.

Strain TA $4^{\mathrm{T}}$ has been deposited in the Deutsche Sammlung von Mikroorganismen und Zellkulturen $\mathrm{GmbH}$, Braunschweig, Germany, as strain DSM $9187^{\mathrm{T}}$.

The type strain is strain TA 4 (= DSM 9187). The properties of this strain are the same as the properties described above for the species.

\section{ACKNOWLEDGMENTS}

We gratefully acknowledge the help of H. P. Roos (Institut für Pflanzenbiologie, Universität Zürich) with electron microscopy. We also thank F. A. Rainey (Deutsche Sammlung von Mikroorganismen und Zellkulturen $\mathrm{GmbH}$, Braunschweig, Germany) for performing the $16 \mathrm{~S}$ rDNA sequence analysis.

\section{REFERENCES}

1. Cashion, P., M. A. Holder-Franklin, J. McCully, and M. Franklin. 1977. A rapid method for the base ratio determination of bacterial DNA. Anal. Biochem. 81:461-466.

2. De Soete, G. 1983. A least squares algorithm for fitting additive trees to proximity data. Psychometrika 48:621-626.

3. Eichler, B., and N. Pfennig. 1988. A new purple sulfur bacterium from stratified freshwater lakes, Amoebobacter purpureus sp. nov. Arch. Microbiol. 149:395-400.

4. Elsden, S. R., M. G. Hilton, and J. M. Waller. 1976. The end products of the metabolism of aromatic amino acids by Clostridia. Arch. Microbiol. 107:283288.

5. Holdeman, L. V., E. P. Cato, and W. E. C. Moore (ed.). 1977. Anaerobe laboratory manual, 4th ed. Department of Anaerobic Microbiology, Virginia Polytechnic Institute and State University, Blacksburg.

6. Holt, J. G., N. R. Krieg, P. H. A. Sneath, J. T. Staley, and S. T. Williams (ed.). 1994. Bergey's manual of determinative bacteriology, 9th ed. Williams \& Wilkins, Baltimore.

7. Jukes, T. H., and C. R. Cantor. 1969. Evolution of protein molecules, p. 21-132. In H. N. Munro (ed.), Mammalian protein metabolism. Academic Press, New York.

8. Jüttner, F. 1988. Quantitative trace analysis of volatile organic compounds. Methods Enzymol. 167:609-616.

9. Jüttner, F. 1990. Distribution of toluene in stratified lakes and river dams of southwest Germany. Verh. Int. Ver. Limnol. 24:279-281.

10. Jüttner, F. 1991. Formation of toluene by microorganisms from anoxic freshwater sediments. Fresenius J. Anal. Chem. 339:785-787.

11. Jüttner, F., and J. Henatsch. 1986. Anoxic hypolimnion is a significant source of biogenic toluene. Nature (London) 323:797-798.

12. Levett, P. N. 1991. Identification of clinically important anaerobes, p. 29-50. In P. N. Levett (ed.), Anaerobic microbiology. A practical approach. Oxford University Press, New York.

13. Mesbah, M., U. Premachandran, and W. Whitman. 1989. Precise measurement of the $\mathrm{G}+\mathrm{C}$ content of deoxyribonucleic acid by high-performance liquid chromatography. Int. J. Syst. Bact. 39:159-167.

14. Pons, J. L., A. Rimbault, J. C. Darbord, and G. Leluan. 1984. Biosynthèse de toluene chez Clostridium aerofoetidum souche WS. Ann. Microbiol. (Inst. Pasteur) 135B:219-222.

15. Süssmuth, R., J. Eberspächer, R. Haag, and W. Springer. 1987. Biochemisch-mikrobiologisches Praktikum. Thieme, Stuttgart, Germany.

16. Tindall, B. J. 1990. A comparative study of the lipid composition of Halobacterium saccharovorum from various sources. Syst. Appl. Microbiol. 13:128130.

17. Tindall, B. J. 1990. Lipid composition of Halobacterium lacusprofundi. FEMS Microbiol. Lett. 66:199-202.

17a.Tindall, B. J. Unpublished data.

18. Widdel, F., and N. Pfennig. 1984. Dissimilatory sulfate- or sulfur-reducing bacteria, p. 675-677. In N. R. Krieg and J. G. Holt (ed.), Bergey's manual of systematic bacteriology, vol. 1. Williams \& Wilkins, Baltimore.

19. Wilkinson, S. G. 1988. Gram-negative bacteria, p. 299-488. In C. Ratledge and S. G. Wilkinson (ed.), Microbial lipids, vol. 1. Academic Press, London.

20. Yokoyama, M. T., and J. R. Carlson. 1981. Production of scatole and $p$-cresol by a rumen Lactobacillus sp. Appl. Environ. Microbiol. 41:71-76.

21. Zehnder, A. J. B. 1988. Biology of anaerobic microorganisms. J. Wiley \& Sons, Inc., New York. 